\title{
Metabolomics Reveals the Alteration of Metabolic Pathway by Alpha-Melanocyte-Stimulating Hormone in B16F10 Melanoma Cells
}

\author{
Seung-Ho Seo ${ }^{1,+}{ }^{\text {, Jae Kwon Jo }}{ }^{1,+}{ }^{+}$, Eun-Ju Kim ${ }^{1}$, Seong-Eun Park ${ }^{1}$, Seo Yeon Shin ${ }^{2}$, \\ Kyung Mok Park ${ }^{2, *}$ and Hong-Seok Son $1, * \mathbb{D}$ \\ 1 School of Korean Medicine, Dongshin University, Naju, Jeonnam 58245, Korea; \\ blue784300@naver.com (S.-H.S.); jojk89@naver.com (J.K.J.); yci3431@naver.com (E.-J.K.); \\ seong9525@naver.com (S.-E.P.) \\ 2 Department of Pharmaceutical Engineering, Dongshin University, Naju, Jeonnam 58245, Korea; \\ ssy33144@naver.com \\ * $\quad$ Correspondence: parkkm@dsu.ac.kr (K.M.P.); hsson@dsu.ac.kr (H.-S.S.); Tel.: +82-32-551-3629 (K.M.P.); \\ +82-61-330-3513 (H.-S.S.) \\ + These authors equally contributed to the work.
}

Academic Editor: Iola F. Duarte

check for Received: 4 July 2020; Accepted: 24 July 2020; Published: 26 July 2020

\begin{abstract}
The purpose of this study was to understand the changes of metabolic pathway induced by alpha-melanocyte-stimulating hormone ( $\alpha$-MSH) in B16F10 melanoma cells in an untargeted metabolomics approach. Cells were treated with $100 \mathrm{nM}$ of $\alpha-\mathrm{MSH}$ and then incubated for $48 \mathrm{~h}$. $\alpha$-MSH increased tyrosinase activity and melanin content by 56.5 and $61.7 \%$, respectively, compared to untreated cells after $48 \mathrm{~h}$ of cultivation. The clear separation between groups was observed in the principal component analysis score plot, indicating that the levels of metabolites of melanoma cells were altered by treatment with $\alpha$-MSH. Metabolic pathways affected by $\alpha$-MSH were involved in some amino acid metabolisms. The increased levels of fumaric acid, malic acid, oxaloacetic acid and citric acid related to the citric acid cycle pathway after $\alpha-\mathrm{MSH}$ treatment suggested enhanced energy metabolism. Metabolic pathways altered by $\alpha-\mathrm{MSH}$ treatment can provide useful information to develop new skin pigmentation inhibitors or anti-obesity drugs.
\end{abstract}

Keywords: $\alpha$-melanocyte-stimulating hormone; melanoma cell; metabolomics; energy metabolism; amino acid metabolism

\section{Introduction}

Melanogenesis can be stimulated by the ultraviolet or visible light-induced alpha-melanocyte-stimulating hormone ( $\alpha$-MSH) in melanocytes [1]. While $\alpha-\mathrm{MSH}$, an endogenous peptide hormone and neuropeptide of the melanocortin family, is well known for its physiological function of stimulation of melanin production, it also plays an important role in controlling appetite and energy balance [2], sexual activity [3] and ischemia and reperfusion-associated injury [4]. The effects of $\alpha$-MSH to protect ischemic damage in various organs, such as brain [5] and gastrointestinal tract [6], have been reported. In addition, several studies have shown that $\alpha$-MSH can reduce UV-induced skin damage through inositol trisphosphate $\left(\mathrm{IP}_{3}\right)$ kinase-Akt pathway [7] and nucleotide excision repair [8]. Potential strategies have been proposed to prevent skin cancer by improving pigmentation with $\alpha$-MSH analogs [9] or cAMP agonists [10]. However, an important concern about $\alpha-\mathrm{MSH}$ is its overproduction causing various skin diseases, such as chloasma, freckles and skin cancer [11]. Therefore, in order to investigate the potential efficacy and side effects of $\alpha-\mathrm{MSH}$, a comprehensive analysis of $\alpha-\mathrm{MSH}$ on the metabolic pathway of cells is required. 
Metabolomics is a very powerful tool that provide a more comprehensive understanding of the effects of biological potential at a specified time in particular environmental conditions [12]. With the development in the last few decades of analytical instruments, such as mass spectrometry and nuclear magnetic resonance spectroscopy, metabolomic analysis of cells has been widely used to perform a complete assessment of functional cellular responses to pathogen infections, toxicity and environmental factors [13]. In addition, studies have reported that metabolites directly initiate cell signaling stages and regulate various biological processes such as post-translational modifications and epigenetic mechanisms [14]. Thus, metabolomic analysis is expected to provide novel insight into the effects of $\alpha-\mathrm{MSH}$.

Melanogenesis by $\alpha-\mathrm{MSH}$ is a complex process that is controlled by tyrosinase and related proteins. The $\alpha$-MSH binds to melanocortin-1 receptor (MC1R) in melanocytes to activate adenylate cyclase, which leads to an elevated level of intracellular cAMP. The expression of tyrosinase is stimulated by cAMP pathway [15]. Tyrosinase mediates hydroxylation of tyrosine into DOPA, followed by a series of processes to synthesize melanin [16]. Therefore, inhibition of tyrosinase has been widely used in the industry to reduce excessive pigmentation [1]. However, as noted, the series of successive melanogenesis pathways do not capture the full range of behaviors of a metabolic network. As metabolic networks generally include various branch points, $\alpha$-MSH can cause alteration of unknown metabolic pathways. However, little effort has been devoted to the metabolic profiling of melanogenesis in melanoma cells. Herein, we applied this strategy to better understand the changes of metabolic pathway induced by $\alpha-\mathrm{MSH}$ in B16F10 melanoma cells in an untargeted approach.

\section{Results}

\subsection{Effect of $\alpha-M S H$ on Tyrosinase Activity and Melanin Synthesis}

To investigate the effect of $\alpha-\mathrm{MSH}$, tyrosinase activity and melanin production in B16F10 melanoma cells were analyzed. As expected, $\alpha$-MSH increased tyrosinase activity and melanin content by $56.5 \%$ and $61.7 \%$, respectively, compared to untreated cells at $48 \mathrm{~h}$ (Figure S1).

\subsection{Metabolite Changes During Cell Culture Period}

Principal component analysis (PCA) was performed to monitor changes in metabolites during $48 \mathrm{~h}$ of melanoma cell culture (Figure 1). The first and second principal component (PC1 and PC2) represented $41.5 \%$ and $16.8 \%$ of the total variance, respectively. The clear separation of samples by cultivation time was observed in the PCA score plot, indicating that metabolites change rapidly during the cell culture period. The differences of metabolites by $\alpha$-MSH were much less than those by the cell culture period. The two groups at $1 \mathrm{~h}$ were not fully distinguishable in the PCA score plot, implying that metabolites were similar to each other. However, the PCA score plot at $24 \mathrm{~h}$ showed clear differentiation, suggesting that the metabolites of melanoma cells can be altered by treatment with $\alpha$-MSH. Based on the fragmentation pattern of National Institute of Standards and Technology (NIST) library and in-house library made by standard chemicals, a total of 52 metabolites were identified in the sample (Table S1). Most metabolites, except malic acid, glutamine, glutamic acid and aspartic acid, increased significantly during the cell culture period (Table S2). Melanoma cells treated with $\alpha$-MSH showed similar metabolite changes but a significant decrease in the content of glucose was observed (Table S3). 


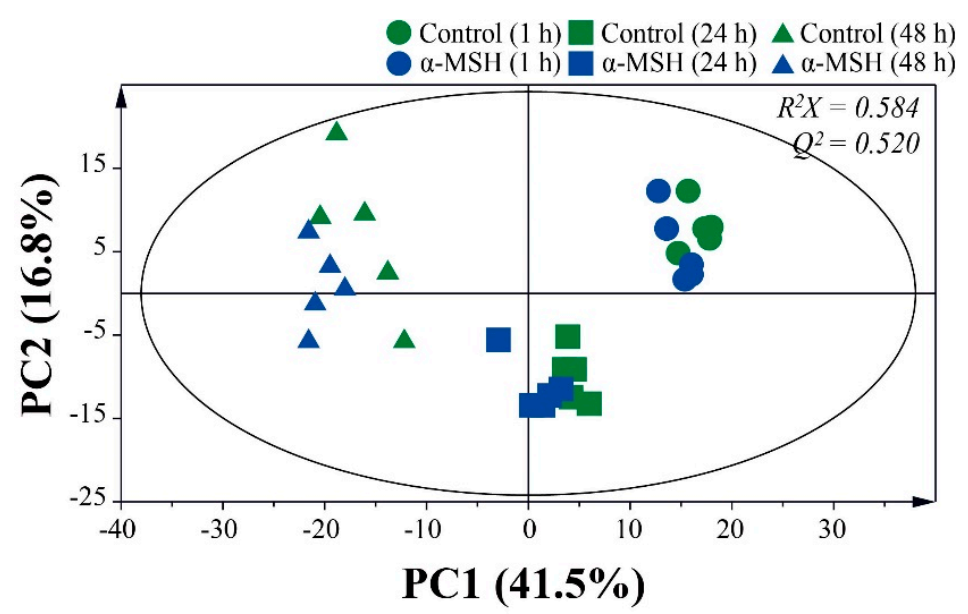

Figure 1. Principal component analysis (PCA) score plot based on the gas chromatography-mass spectrometry (GC-MS) data sets during $48 \mathrm{~h}$ of melanoma cell culture.

\subsection{Effect of $\alpha-M S H$ on Metabolic Changes After 48 h of Cell Culture}

PCA was performed to investigate the metabolic differences between control and $\alpha$-MSH during cell culture period (Figure 2A). The two groups at 1 and $24 \mathrm{~h}$ of cultivation were not completely distinguished in the PCA score plot, indicating that the metabolite profiles between the groups were not significantly different. However, after $48 \mathrm{~h}$ of cell culture, separation between the groups by PC2 was observed, suggesting that the metabolites of melanoma cells can be altered by treatment with $\alpha-\mathrm{MSH}$. To maximize separation and find potential biomarkers, partial least squares-discriminant analysis (PLS-DA) model for supervised pattern recognition was further applied between the experimental groups. The PLS-DA score plot (Figure 2B) showed that the two groups were clearly separated from each other, indicating that there was a significant metabolite difference between the two groups. The permutation test supported the validity of this PLS-DA model. To find the metabolite responsible for the separation of this PLS-DA model, the variables of variable importance in projection (VIP) were determined. Potential metabolic biomarkers were selected based on VIP $>1.0$ and the corrected $p$ values. The $\alpha-\mathrm{MSH}$ treated melanoma cells were characterized by higher levels of citric acid, glycine, oxaloacetic acid, malic acid, lactic acid, glycolic acid, fumaric acid and glutamine but lower levels of inositol, compared to the control (Table 1). Interestingly, the changes in levels of malic acid, inositol and glutamine showed opposite results to the change pattern according to the cell culture period. The levels of fumaric acid did not change significantly with cell culture but $\alpha$-MSH-treated samples showed significantly higher levels than control. It is presumed that these metabolites are related to the metabolic pathway that changes dramatically by $\alpha$-MSH treatment.

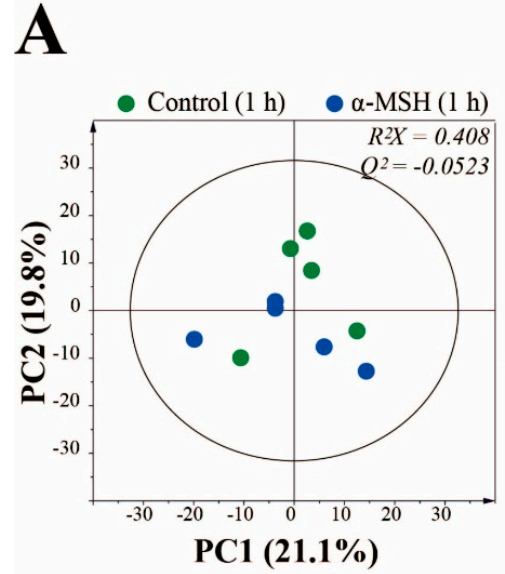

PC1 (21.1\%)
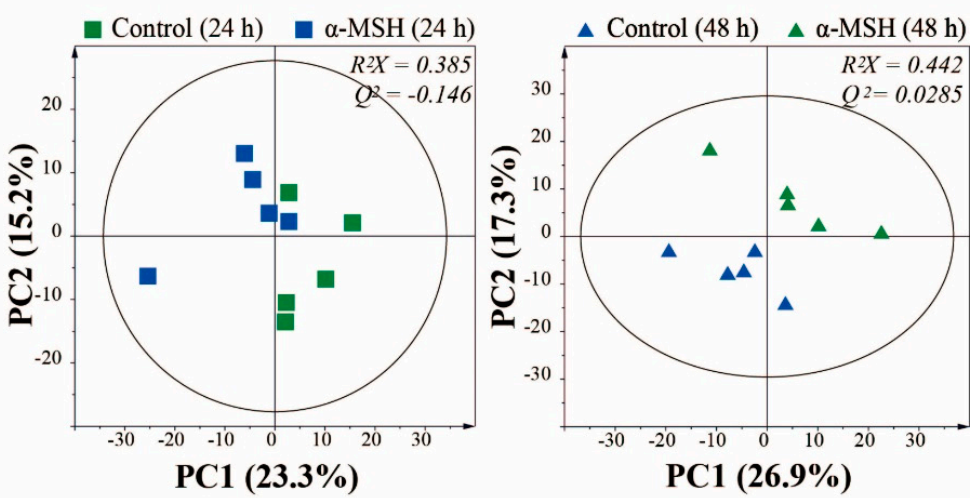

Figure 2. Cont. 

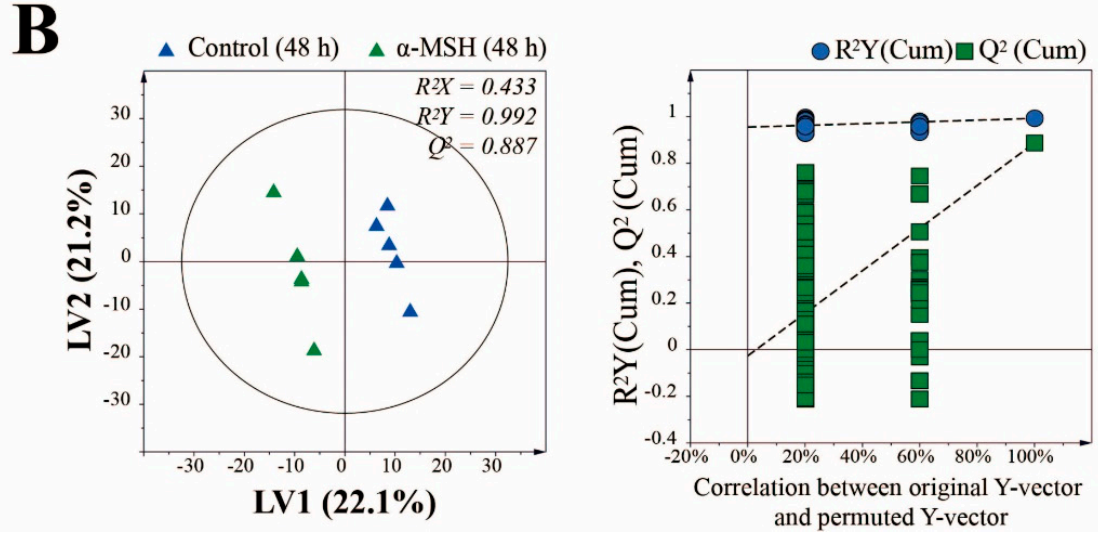

Figure 2. (A) PCA score plots derived from GC-MS data at 1, 24 and $48 \mathrm{~h}$ of melanoma cell culture. (B) partial least squares-discriminant analysis (PLS-DA) score plot between control and $\alpha$-MSH treated group after $48 \mathrm{~h}$ of incubation validated by a permutation test.

Table 1. Significantly different metabolites between the control and $\alpha-\mathrm{MSH}$ treated groups, after $48 \mathrm{~h}$ of incubation of melanoma cells.

\begin{tabular}{|c|c|c|c|c|c|c|c|}
\hline No. & Metabolites & VIP Score & $\begin{array}{c}\alpha \text {-MSH/ } \\
\text { Control } \\
(\uparrow / \downarrow)^{1}\end{array}$ & $p$ Value & $q$ Value $^{2}$ & Significance $^{3}$ & $\begin{array}{c}\text { Control } \\
48 \mathrm{~h} / 1 \mathrm{~h} \\
(\uparrow / \downarrow)\end{array}$ \\
\hline 1 & Citric acid & 2.15 & $\uparrow$ & 0.0001 & 0.002 & *** & $\uparrow * * *$ \\
\hline 2 & Glycine & 2.02 & $\uparrow$ & 0.0002 & 0.005 & $* * *$ & $\uparrow * * *$ \\
\hline 3 & $\begin{array}{c}\text { Oxaloacetic } \\
\text { acid }\end{array}$ & 2.01 & $\uparrow$ & 0.0002 & 0.007 & $* * *$ & $\uparrow * * *$ \\
\hline 4 & Malic acid & 1.97 & $\uparrow$ & 0.0004 & 0.010 & $* *$ & $\downarrow * *$ \\
\hline 5 & Inositol & 1.94 & $\downarrow$ & 0.0007 & 0.012 & $* *$ & $\uparrow * * *$ \\
\hline 6 & Lactic acid & 1.93 & $\uparrow$ & 0.0028 & 0.014 & $* *$ & $\uparrow * * *$ \\
\hline 7 & $\begin{array}{l}\text { Glycolic } \\
\text { acid }\end{array}$ & 1.92 & $\uparrow$ & 0.0025 & 0.017 & ** & $\uparrow * * *$ \\
\hline 8 & $\begin{array}{c}\text { Fumaric } \\
\text { acid }\end{array}$ & 1.84 & $\uparrow$ & 0.0039 & 0.019 & ** & - \\
\hline 9 & Glutamine & 1.81 & $\uparrow$ & 0.0100 & 0.021 & * & $\downarrow *$ \\
\hline
\end{tabular}

${ }^{1}$ The vertical arrows $(\downarrow$ and $\uparrow)$ represent a decrease or increase in metabolite levels after $48 \mathrm{~h}$ of incubation.

${ }^{2}$ False discovery rate (FDR). The false discovery rate at $5 \%$ was applied to all tests to correct for multiple testing.

${ }^{3}$ Symbols $\left({ }^{*}\right)$ indicate significant difference $\left({ }^{*} p<0.05 ; * * p<0.01 ; * * * p<0.001\right)$.

\subsection{Effect of $\alpha-M S H$ on Metabolic Pathway Alteration}

Metabolic pathway analysis was performed to identify relevant metabolic pathways affected by $\alpha$-MSH (Figure 3). This analysis shows metabolic pathways by enrichment analysis and impact values by topology analysis. Eight important pathways were identified, based on the pathway impact and $-\log (p)$ value (Table 2). Metabolic pathways affected by $\alpha-\mathrm{MSH}$ were involved in alanine-aspartate and glutamate metabolism, phenylalanine-tyrosine and tryptophan biosynthesis, glutamine and glutamate metabolism, cysteine and methionine metabolism, glycine-serine and threonine metabolism, citrate cycle, taurine and hypotaurine metabolism and phenylalanine metabolism. Figure 3 shows a schematic of the affected metabolic pathways by $\alpha-\mathrm{MSH}$ treatment. In $\alpha$-MSH treated cells, the content of some metabolites, including tyrosine, fumaric acid, malic acid, oxaloacetic acid, citric acid, lactic acid, glutamine and glycine, was significantly different from that of control cells. 


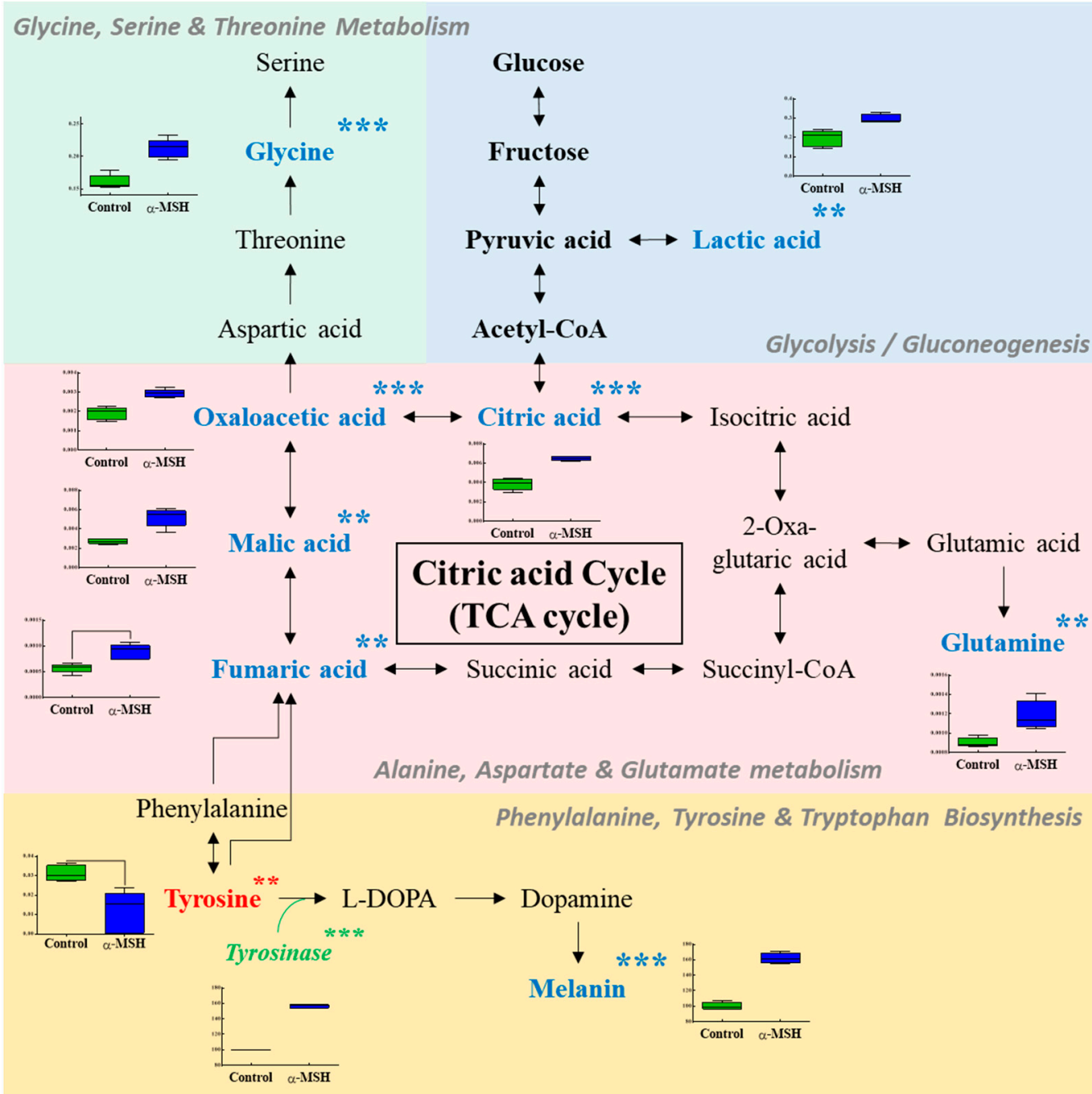

Figure 3. Schematic of the metabolic pathway related to the effects of $\alpha$-MSH. The metabolites in blue and red represent the potential biomarkers that are increased or decreased by $\alpha$-MSH treatment, respectively. Symbols $\left({ }^{*}\right)$ indicate significant difference $\left({ }^{*} p<0.05 ;{ }^{* *} p<0.01\right.$; $\left.{ }^{* *} p<0.001\right)$.

Table 2. Metabolic pathways affected by $\alpha-\mathrm{MSH}$ on B16F10 melanoma cell.

\begin{tabular}{cccccc}
\hline No. & Metabolic Pathways & Total & Hits & $-\log (p)$ & Impact \\
\hline 1 & $\begin{array}{c}\text { Alanine, aspartate and } \\
\text { glutamate metabolism }\end{array}$ & 28 & 7 & 10.99 & 0.63 \\
2 & $\begin{array}{c}\text { Phenylalanine, tyrosine } \\
\text { and tryptophan } \\
\text { biosynthesis }\end{array}$ & 4 & 2 & 5.14 & 1.00 \\
3 & $\begin{array}{c}\text { Glutamine and glutamate } \\
\text { metabolism }\end{array}$ & 6 & 2 & 4.26 & 0.50 \\
4 & $\begin{array}{c}\text { Cysteine and methionine } \\
\text { metabolism }\end{array}$ & 33 & 4 & 3.93 & 0.33 \\
5 & $\begin{array}{c}\text { Glycine, serine and } \\
\text { threonine metabolism }\end{array}$ & 33 & 4 & 3.93 & 0.46 \\
6 & $\begin{array}{c}\text { Citrate cycle (TCA cycle) } \\
\text { Taurine and hypotaurine } \\
\text { metabolism }\end{array}$ & 20 & 4 & 5.82 & 0.28 \\
8 & Phenylalanine metabolism & 10 & 2 & 3.68 & 0.71 \\
\hline & $\quad$ & 2 & 3.25 & 0.36 \\
\hline
\end{tabular}




\section{Discussion}

The $\alpha$-MSH exerts its effect by binding to 5 subtypes of melanocortin receptors (MC1-R to MC5-R), which are known to involve the melanocortins signal, including $\alpha-\mathrm{MSH}$ [17]. Activation of different MC-Rs regulates different cellular functions and behaviors in various types of cells. For example, MC4-R contributes to the regulation of food intake, energy consumption and fatty acid oxidation in skeletal muscle [18]. On the other hand, activation of MC1-R mediates melanin production and temperature regulation [19]. While MC1-R was originally proven in melanocyte-derived melanoma cells, there is now also evidence that it is expressed in many types of cells, including immune cells [20]. Therefore, it is important to identify differences in cell metabolism according to the activation of different subtypes of MC-Rs but few studies have been conducted to date. The interaction between $\alpha$-MSH and MC1-R promotes melanogenesis through the cAMP/PKA pathway. However, there was little interest in the metabolism altered by $\alpha-\mathrm{MSH}$ in melanoma cells, except for this pathway. Maresca et al. [21] have discovered a new $\alpha-\mathrm{MSH} /$ peroxisome proliferator activated receptor- $\gamma(\operatorname{PPAR} \gamma)$ connection that influenced both pigmentation and proliferation in B16-F10 cells. Although $\alpha-\mathrm{MSH}$ activity as a mitogenic agent in melanocytes is well known, some studies have shown that the $\alpha-\mathrm{MSH} P P A R \gamma$ pathway down-regulated proliferation in melanoma cell lines [22].

Although many studies of melanogenesis by $\alpha-\mathrm{MSH}$ in melanoma cells have been published, little attention has been paid to the altered metabolism by $\alpha-\mathrm{MSH}$ in melanoma cells. Metabolomics can provide a comprehensive identification of pathway alterations by treatment. To the best of our knowledge, this is the first study to identify metabolite changes in melanoma cells by $\alpha$-MSH treatment. In this study, an increase in fumaric acid, malic acid, oxaloacetic acid and citric acid related to the citric acid cycle pathway were observed after $\alpha$-MSH treatment. However, the administration of $\alpha$-MSH suppressed citric acid synthase in a rodent model [23]. The increase of metabolites of citric acid cycle by $\alpha$-MSH seems to enhance the energy metabolism. These results may be related to other findings that $\alpha$-MSH can control body weight through its hypermetabolic and hyperthermic effects [24]. It is well known that the hypothalamic melanocortin system is involved in thermoregulation [25]. Meanwhile, there are some reports that $\alpha-\mathrm{MSH}$ is involved in energy balance by regulating appetite stimulation based on the relationship with orexigenic neuropeptides and leptin [26,27]. Kravchychyn et al. [28] reported that the long-term $\alpha$-MSH treatment promoted a significant improvement in body adiposity through the regulation of anorexigenic/orexigenic pathways in obese adolescents. From the above results, $\alpha$-MSH appears to be an important substance involved in the complex mechanisms of energy balance control.

The signal pathway of $\alpha$-MSH associated with hypermetabolic effects can be an attractive candidate drug target for the treatment of obesity. For example, the MC4-R activation plays an important role in weight regulation, which provides insight into the mechanisms that can be used as a new target for obesity [29]. The intracellular mechanism by which $\alpha$-MSH activates energy metabolism is not well understood but two possible hypotheses from previous studies are possible. First, according to the results of Møller et al. [22], $\alpha$-MSH stimulates glucose uptake by an unknown mechanism, boosting central effects on metabolism. However, in this study, there was no significant difference in glucose content between the control and $\alpha$-MSH treated groups. Second, the metabolic pathway of tyrosine degradation ends up as fumaric acid and acetoacetate, which can enter the citric acid cycle [30]. In this study, acetoacetate was not detected but the content of fumaric acid increased significantly with $\alpha$-MSH treatment. However, there are no reports of $\alpha-\mathrm{MSH}$ promoting energy metabolism via glucose uptake or tyrosine degradation. Although increased tyrosinase activity by $\alpha$-MSH may affect the energy metabolic pathway, further studies are needed to demonstrate this. Since the metabolic network generally contains various branches, changes in the metabolic pathway by $\alpha$-MSH can then lead to unknown metabolic pathway changes. Hill et al. [31] reported that the accumulation of cAMP induced by $\alpha-\mathrm{MSH}$ showed a strong positive correlation with the ability of B16 melanoma clones to form pulmonary tumor colonies, suggesting that it is linked with biochemical pathways that are responsible for the formation of experimental metastasis. In this study, $\alpha-\mathrm{MSH}$ treatment did not 
increase cellular proliferation. Although the hypermetabolic effects by $\alpha$-MSH may be associated with cancer proliferation and metastasis, there is no report that $\alpha-\mathrm{MSH}$ is related to cancer cell proliferation and metastasis. Further studies are needed on the effects of $\alpha-\mathrm{MSH}$ on metabolism change of cancer cell.

Although this study focused on the intracellular metabolome, metabolic profiling of medium supernatants could provide complementary information on the metabolites consumed and excreted by cells. However, the culture medium contains specific compounds, including amino acids, vitamins, inorganic salts and glucose, to provide energy sources and regulate the cell cycle [32]. In this study, medium supernatants were not analyzed because compounds present in the culture medium can be mixed with metabolites released from the cells, ultimately obscuring the profile of the secretome. Daskalaki et al. [33] reported that multiple and cell-free medium combinations should be tested to exclude the influence of culture media when designing a cell secretion-based metabolite profiling experiments. Another limitation of the current study is that the data obtained are based on an up-regulated pigmentary model of B16F10 melanoma cells. Tumor cells metabolize differently from normal cells. For example, a tumor cell may have Warburg effect that it depends on the metabolic pathways of glycolysis or gluconeogenesis to meet their metabolic demand [34]. Since melanogenesis in B16F10 melanoma cells is several times up-regulated compared to normal melanocytes, further studies on comparative metabolic analysis using normal melanocytes are needed to confirm our results.

\section{Materials and Methods}

\subsection{Cell Culture}

The B16F10 melanoma cells (CRL-6475) were purchased from the American Type Culture Collection (ATCC, Manassas, VA, USA). Cells were incubated in Dulbecco's modified Eagle's medium (DMEM) with $10 \%$ fetal bovine serum and $1 \%$ penicillin/streptomycin in air containing $5 \% \mathrm{CO}_{2}$ at $37{ }^{\circ} \mathrm{C}$. Cells were sub-cultured every 3 days. Cells were seeded in 12 -well plates, at a density of $1 \times 10^{5}$ cells/well and incubated for $24 \mathrm{~h}$. $\alpha$-MSH $(100 \mathrm{nM})$ was added to the wells of the plate and the cells then incubated for an additional $48 \mathrm{~h}$. Through the MTT assay, we determined the concentration (100 nM) that could have effects without affecting the viability of B16F10 cells compared to the untreated control group.

\subsection{Measurement of Cellular Melanin Contents}

Cell pellets were lysed in $\mathrm{NaOH}(1 \mathrm{~N})$ in $10 \% \mathrm{DMSO}$ at $80^{\circ} \mathrm{C}$ for $1 \mathrm{~h}$. The relative melanin content was determined by measuring absorbance at the $490 \mathrm{~nm}$ using a microplate reader as previously described [35].

\subsection{Measurement of Cellular Tyrosinase Activity}

Cells were washed using cold-phosphate-buffered saline (PBS) and lysed with Pro-Prep lysis buffer (iNtRON Biotechnology, Seongnam, Korea). The cell lysate was purified by centrifugation at $12,000 \mathrm{rpm}$ for $15 \mathrm{~min}$ at $4{ }^{\circ} \mathrm{C}$. Enzyme activity was normalized to protein concentration $(30 \mu \mathrm{g})$, as determined by Bradford assay. Cellular tyrosinase and L-DOPA solution (0.1 M sodium phosphate) were evaluated at $37^{\circ} \mathrm{C}$ for $1 \mathrm{~h}$. The absorbance at $405 \mathrm{~nm}$ was measured by microplate reader.

\subsection{Sample Preparation}

Cells were washed with $0.9 \% \mathrm{NaCl}$. Then, $200 \mu \mathrm{L}$ of distilled water and $200 \mu \mathrm{L}$ of methanol were added to the cells on ice. Each well of the plate was scraped with a cell scraper. The cell extract was then transferred to an Eppendorf tube containing $200 \mu \mathrm{L}$ of cold chloroform. Cells were stirred for $20 \mathrm{~min}$ on a shaker, then centrifuged at a minimum of $16,100 \times g$ for $5 \mathrm{~min}$ at $4{ }^{\circ} \mathrm{C}$. Polar (upper) phase $(100 \mu \mathrm{L})$ was transferred to a vial, without touching the interphase. Quality control (QC) samples were prepared by collecting the same volume $(10 \mu \mathrm{L})$ of polar phase from each sample prior to the drying process. For blank samples, the same amount of water as the sample was added into an Eppendorf 
tube. After the polar phase was dried on a rotary vacuum evaporator at $-4{ }^{\circ} \mathrm{C}$, vials were capped and stored at $-80^{\circ} \mathrm{C}$ until analysis.

\subsection{Sample Derivatization}

After freeze drying, $80 \mu \mathrm{L}$ of $O$-methoxyamine hydrochloride $(20 \mathrm{mg} / \mathrm{mL})$ in pyridine solution was added to each sample. After vortex-mixing each sample for $30 \mathrm{~s}$, all samples were incubated at $30{ }^{\circ} \mathrm{C}$ for $90 \mathrm{~min}$ in the dark. After adding $30 \mu \mathrm{L}$ of $N$-methyl- $N$-trimethylsilyl-trifluoroacetamide containing $1 \%$ trimethylchlorosilane, silylation process was performed. Each sample was vortex mixed for $30 \mathrm{~s}$ and then incubated at $37^{\circ} \mathrm{C}$ for $30 \mathrm{~min}$. Ten $\mu \mathrm{L}$ of ribitol $(0.5 \mathrm{mg} / \mathrm{L})$ was added as an internal standard (IS). After centrifuging the sample at 13,000 rpm for $10 \mathrm{~min}, \mathrm{GC}-\mathrm{MS}$ analysis was performed on the supernatant.

\subsection{GC-MS Analysis}

Derivatized samples were analyzed using GC-MS (QP2020, Shimadzu, Kyoto, Japan). Rtx-5MS with fused silica capillary column $(30 \mathrm{~m} \times 0.25 \mathrm{~mm}$ ID, J\&W Scientific, CA) was used for the separation of metabolites. The front inlet temperature was $230^{\circ} \mathrm{C}$. The column temperature was maintained at $80^{\circ} \mathrm{C}$ for $2 \mathrm{~min}$ isothermally and then raised by $15^{\circ} \mathrm{C} / \mathrm{min}$ to $330^{\circ} \mathrm{C}$ and held there for 6 min isothermally. The transfer line and ion source temperatures were 250 and $200{ }^{\circ} \mathrm{C}$, respectively. Ionization was achieved with a $70 \mathrm{eV}$ electron beam. The helium gas flow rate through the column was $1 \mathrm{~mL} / \mathrm{min}$. Twenty scans per second were recorded in a mass range of $85-500 \mathrm{~m} / \mathrm{z}$. Chromatograms and mass spectra were obtained using Shimadzu GC solution (Shimadzu, Kyoto, Japan). To measure the stability and performance of the instrument along with the reproducibility of the sample treatment procedure, QC samples were analyzed every 5 samples during the run. QC samples were clustered centrally in the PCA score plot, ensuring the reliability of metabolomics analysis (Figure S2).

\subsection{Data Processing and Statistical Analysis}

GC-MS data was converted to a netCDF format file and processed with MetAlign software for peak detection and alignment [36]. The MetAlign parameters were set according to the AIoutput scaling requirements - a peak slope factor of 2, peak threshold factor of 4, peak threshold of 10 and average peak width at half height of 25, which corresponds to a retention time of 3-26 min and mass range of 85-500 for GC-MS. The resulting data (CSV-format file) was imported into AIoutput software for peak identification and prediction [37]. Feature intensities were normalized according to the intensity of IS (RT 11.205, m/z 147) prior to multivariate statistical analyses. The height of each feature was divided by the height of IS detected in that particular sample. PCA and PLS-DA of GC-MS data were performed to visualize the variance of metabolites using SIMCA-P 15.0 (Umetrics, Umea, Sweden). For model validation, 200-fold cross-validation was performed. Metabolites with VIP score greater than 1.0 and $p$ value from Students $t$-test lower than 0.05 were considered metabolites that were capable of discriminating groups. To correct for multiple testing, the positive false discovery rate (type 1 error) was used by computing $q$-values after $t$-test. Identification of metabolites was performed by comparing the mass spectrum with AIoutput software, NIST 14.0 library and the human metabolome database (HMDB, http://www.hmdb.ca).

\subsection{Metabolic Pathway Analysis}

Metabolic pathway analysis was performed with MetaboAnalyst web software (metaboanalyst.ca) and the Kyoto Encyclopedia of Genes and Genomes (KEGG), by filtering the dataset using an FDR-adjusted $p$ value $<0.05$ and impact value $>0.1$, to reveal how significant metabolites are involved in different pathways [38]. 


\section{Conclusions}

Our study indicates that the effects of $\alpha-\mathrm{MSH}$ are a rearrangement of citric acid cycle pathways and some amino acid metabolisms through several important metabolite changes. A more in-depth analysis of these mechanisms could provide useful information to develop new skin pigmentation inhibitors or anti-obesity drugs.

Supplementary Materials: The following are available online, Table S1: Identified metabolites by GC-MS in melanoma cells, Table S2: Significantly changed metabolites in melanoma cells after $48 \mathrm{~h}$ of incubation, Table S3: Significantly changed metabolites in melanoma cells treated with $\alpha$-MSH after 48 h of incubation, Figure S1: Box plots of tyrosinase activity and melanin content, Figure S2: PCA score plot derived from GC-MS data of experimental samples and QC samples.

Author Contributions: Conceptualization, S.-H.S., J.K.J. and H.-S.S.; Data curation, S.-H.S., J.K.J., K.M.P., S.-E.P., E.-J.K. and S.Y.S.; Investigation, E.-J.K. and S.Y.S.; Methodology, K.M.P. and H.-S.S.; Software, S.-E.P. and E.-J.K.; Writing-original draft, S.-H.S., J.K.J.; Writing—review \& editing, K.M.P. and H.-S.S. All authors have read and agreed to the published version of the manuscript.

Funding: This work was supported by the National Research Foundation of Korea (NRF) grant funded by the Korea government (2019R1C1C1002208 and 2018R1D1A1B07050948).

Conflicts of Interest: The authors declare no conflict of interest.

\section{References}

1. Chao, W.-W.; Su, C.-C.; Peng, H.-Y.; Chou, S.-T. Melaleuca quinquenervia essential oil inhibits $\alpha$-melanocyte-stimulating hormone-induced melanin production and oxidative stress in B16 melanoma cells. Phytomedicine 2017, 34, 191-201. [CrossRef] [PubMed]

2. Morton, G.J.; Cummings, D.E.; Baskin, D.G.; Barsh, G.S.; Schwartz, M.W. Central nervous system control of food intake and body weight. Nature 2006, 443, 289-295. [CrossRef] [PubMed]

3. Hallam, T.J.; Spana, C.; Earle, D.C.; Shadiack, A.M.; Sharma, S.D. Melanocortins in the treatment of male and female sexual dysfunction. Curr. Top. Med. Chem. 2007, 7, 1137-1144. [CrossRef]

4. Varga, B.; Gesztelyi, R.; Juhasz, B.; Haines, D.; Szabo, A.M.; Kemeny-Beke, A.; Antal, M.; Vecsernyes, M.; Juhasz, B.; Tosaki, A. Protective Effect of Alpha-Melanocyte-Stimulating Hormone ( $\alpha$-MSH) on the Recovery of Ischemia/Reperfusion (I/R)-Induced Retinal Damage in A Rat Model. J. Mol. Neurosci. 2013, 50, 558-570. [CrossRef] [PubMed]

5. Harazin, A.; Bocsik, A.; Barna, L.; Kincses, A.; Váradi, J.; Fenyvesi, F.; Tubak, V.; Deli, M.; Vecsernyes, M. Protection of cultured brain endothelial cells from cytokine-induced damage by $\alpha$-melanocyte stimulating hormone. PeerJ 2018, 6, e4774. [CrossRef] [PubMed]

6. Váradi, J.; Harazin, A.; Fenyvesi, F.; Réti-Nagy, K.; Gogolák, P.; Vámosi, G.; Bacskay, I.; Fehér, P.; Ujhelyi, Z.; Vasvari, G.; et al. Alpha-Melanocyte Stimulating Hormone Protects against Cytokine-Induced Barrier Damage in Caco-2 Intestinal Epithelial Monolayers. PLoS ONE 2017, 12, e0170537. [CrossRef]

7. Kadekaro, A.L.; Kavanagh, R.; Kanto, H.; Terzieva, S.; Hauser, J.; Kobayashi, N.; Schwemberger, S.; Cornelius, J.; Babcock, G.; Shertzer, H.G.; et al. Alpha-melanocortin and endothelin-1 activate antiapoptotic pathways and reduce DNA damage in human melanocytes. Cancer Res. 2005, 65, 4292-4299. [CrossRef]

8. Bohm, M.; Wolff, I.; Scholzen, T.E.; Robinson, S.J.; Healy, E.; Luger, T.A.; Schwarz, T.; Schwarz, A. Alpha-melanocyte-stimulating hormone protects from ultraviolet radiation-induced apoptosis and DNA damage. J. Biol. Chem. 2005, 280, 5795-5802. [CrossRef]

9. Gao, F.; Sihver, W.; Jurischka, C.; Bergmann, R.; Haase-Kohn, C.; Mosch, B.; Steinbach, J.; Carta, D.; Bolzati, C.; Calderan, A.; et al. Radiopharmacological characterization of $64 \mathrm{Cu}$-labeled $\alpha$-MSH analogs for potential use in imaging of malignant melanoma. Amino Acids 2015, 48, 833-847. [CrossRef]

10. Passeron, T.; Namiki, T.; Passeron, H.J.; Le Pape, E.; Hearing, V.J. Forskolin Protects Keratinocytes from UVB-Induced Apoptosis and Increases DNA Repair Independent of its Effects on Melanogenesis. J. Investig. Dermatol. 2009, 129, 162-166. [CrossRef]

11. Zhang, X.; Li, J.; Li, Y.; Liu, Z.; Lin, Y.; Huang, J. Anti-melanogenic effects of epigallocatechin-3-gallate (EGCG), epicatechin-3-gallate (ECG) and gallocatechin-3-gallate (GCG) via down-regulation of cAMP/CREB /MITF signaling pathway in B16F10 melanoma cells. Fitoterapia 2020, 145, 104634. [CrossRef] [PubMed] 
12. Gioria, S.; Vicente, J.L.; Barboro, P.; La Spina, R.; Tomasi, G.; Urban, P.; Kinsner-Ovaskainen, A.; François, R.; Chassaigne, H. A combined proteomics and metabolomics approach to assess the effects of gold nanoparticlesin vitro. Nanotoxicology 2016, 10, 736-748. [CrossRef] [PubMed]

13. Lane, A.N.; Higashi, R.M.; Fan, T.W.-M. NMR and MS-based Stable Isotope-Resolved Metabolomics and applications in cancer metabolism. TrAC Trends Anal. Chem. 2019, 120, 115322. [CrossRef]

14. Johnson, C.H.; Ivanisevic, J.; Siuzdak, G. Metabolomics: Beyond biomarkers and towards mechanisms. Nat. Rev. Mol. Cell Biol. 2016, 17, 451-459. [CrossRef] [PubMed]

15. D’Mello, S.A.N.; Finlay, G.J.; Baguley, B.C.; Askarian-Amiri, M.E. Signaling Pathways in Melanogenesis. Int. J. Mol. Sci. 2016, 17, 1144. [CrossRef] [PubMed]

16. Muñoz-Muñoz, J.L.; Garcia-Molina, F.; Varón, R.; Tudela, J.; Garcia-Canovas, F.; Rodriguez-Lopez, J.N. Generation of hydrogen peroxide in the melanin biosynthesis pathway. Biochim. Biophys. Acta BBA Proteins Proteom. 2009, 1794, 1017-1029. [CrossRef]

17. Brzoska, T.; Luger, T.A.; Maaser, C.; Abels, C.; Böhm, M. $\alpha$-Melanocyte-Stimulating Hormone and Related Tripeptides: Biochemistry, Antiinflammatory and Protective Effects in Vitro and in Vivo and Future Perspectives for the Treatment of Immune-Mediated Inflammatory Diseases. Endocr. Rev. 2008, 29, 581-602. [CrossRef]

18. An, J.J.; Rhee, Y.; Kim, S.H.; Kim, D.M.; Han, D.-H.; Hwang, J.H.; Jin, Y.-J.; Cha, B.-S.; Baik, J.-H.; Lee, W.T.; et al. Peripheral Effect of $\alpha$-Melanocyte-stimulating Hormone on Fatty Acid Oxidation in Skeletal Muscle. J. Biol. Chem. 2006, 282, 2862-2870. [CrossRef]

19. D'Agostino, G.; Diano, S. Alpha-melanocyte stimulating hormone: Production and degradation. J. Mol. Med. 2010, 88, 1195-1201. [CrossRef]

20. Andersen, G.N.; Nagaeva, O.; Mandrika, I.; Petrovska, R.; Muceniece, R.; Mincheva-Nilsson, L.; Wikberg, J.E.S. MC1receptors are constitutively expressed on leucocyte subpopulations with antigen presenting and cytotoxic functions. Clin. Exp. Immunol. 2001, 126, 441-446. [CrossRef]

21. Maresca, V.; Flori, E.; Camera, E.; Bellei, B.; Aspite, N.; Ludovici, M.; Catricalà, C.; Cardinali, G.; Picardo, M. Linking $\alpha \mathrm{MSH}$ with PPAR $\gamma$ in B16-F10 melanoma. Pigment. Cell Melanoma Res. 2012, 26, 113-127. [CrossRef] [PubMed]

22. Møller, C.L.; Kjøbsted, R.; Enriori, P.J.; Jensen, T.E.; Garcia-Rudaz, C.; Litwak, S.A.; Raun, K.; Wojtaszewski, J.F.P.; Wulff, B.S.; Cowley, M.A. $\alpha$-MSH Stimulates Glucose Uptake in Mouse Muscle and Phosphorylates Rab-GTPase-Activating Protein TBC1D1 Independently of AMPK. PLoS ONE 2016, 11, e0157027. [CrossRef]

23. Feichtinger, R.G.; Pétervári, E.; Zopf, M.; Vidali, S.; Aminzadeh-Gohari, S.; Mayr, J.A.; Kofler, B.; Balaskó, M. Effects of alpha-melanocyte-stimulating hormone on mitochondrial energy metabolism in rats of different age-groups. Neuropeptides 2017, 64, 123-130. [CrossRef] [PubMed]

24. Rostás, I.; Füredi, N.; Tenk, J.; Miko, A.; Solymár, M.; Soós, S.; Székely, M.; Pétervári, E.; Balaskó, M. Age-related alterations in the central thermoregulatory responsiveness to alpha-MSH. J. Therm. Biol. 2015, 49, 9-15. [CrossRef]

25. Roh, E.; Kim, M.-S. Brain Regulation of Energy Metabolism. Endocrinol. Metab. 2016, 31, 519-524. [CrossRef] [PubMed]

26. Hoggard, N.; Johnstone, A.M.; Faber, P.; Gibney, E.R.; Elia, M.; Lobley, G.; Rayner, V.; Horgan, G.; Hunter, L.; Bashir, S.; et al. Plasma concentrations of alpha-MSH, AgRP and leptin in lean and obese men and their relationship to differing states of energy balance perturbation. Clin. Endocrinol. 2004, 61, 31-39. [CrossRef]

27. Dâmaso, A.R.; Ganen, A.D.P.; Sanches, P.L.; Corgosinho, F.; Tock, L.; Oyama, L.M.; Tock, L.; Nascimento, C.M.O.D.; Tufik, S.; De Mello, M.T. Hyperleptinemia in obese adolescents deregulates neuropeptides during weight loss. Peptides 2011, 32, 1384-1391. [CrossRef]

28. Kravchychyn, A.C.P.; Campos, R.M.D.S.; Corgosinho, F.C.; Masquio, D.C.L.; Vicente, S.E.D.C.F.; Ferreira, Y.A.M.; Silva, P.L.; Ganen, A.D.P.; E Oyama, L.M.; Tock, L.; et al. The Long-Term Impact of High Levels of Alpha-Melanocyte-Stimulating Hormone in Energy Balance Among Obese Adolescents. Ann. Nutr. Metab. 2018, 72, 279-286. [CrossRef]

29. Fani, L.; Bak, S.; Delhanty, P.; Van Rossum, E.F.C.; Akker, E.L.V.D. The melanocortin-4 receptor as target for obesity treatment: A systematic review of emerging pharmacological therapeutic options. Int. J. Obes. 2013, 38, 163-169. [CrossRef] 
30. Matthews, D.E. An overview of phenylalanine and tyrosine kinetics in humans. J. Nutr. 2007, 137, 1549S-1575S. [CrossRef]

31. Hill, S.E.; Rees, R.C.; MacNeil, S. A positive association between agonist-induced cyclic AMP production in vitro and metastatic potential in murine B16 melanoma and hamster fibrosarcoma. Clin. Exp. Metastasis 1990, 8, 461-474. [CrossRef] [PubMed]

32. Causon, T.; Hann, S. Review of sample preparation strategies for MS-based metabolomic studies in industrial biotechnology. Anal. Chim. Acta 2016, 938, 18-32. [CrossRef] [PubMed]

33. Daskalaki, E.; Pillon, N.J.; Krook, A.; Wheelock, C.E.; Checa, A. The influence of culture media upon observed cell secretome metabolite profiles: The balance between cell viability and data interpretability. Anal. Chim. Acta 2018, 1037, 338-350. [CrossRef]

34. Warburg, O. The metabolism of carcinoma cells. J.Cancer Res. 1925, 9, 148-163. [CrossRef]

35. Lee, C.J.; Park, S.K.; Kang, J.Y.; Kim, J.M.; Yoo, S.K.; Han, H.J.; Kim, D.; Heo, H.J. Melanogenesis regulatory activity of the ethyl acetate fraction from Arctium lappa L. leaf on $\alpha-\mathrm{MSH}$-induced B16/F10 melanoma cells. Ind. Crops Prod. 2019, 138, 111581. [CrossRef]

36. Lommen, A. MetAlign: Interface-driven, versatile metabolomics tool for hyphen-ated full-scan mass spectrometry data preprocessing. Anal. Chim. 2009, 81, 3079-3086. [CrossRef]

37. Tsugawa, H.; Bamba, T.; Shinohara, M.; Nishiumi, S.; Yoshida, M.; Fukusaki, E. Practical non-targeted gas chromatography/mass spectrometry-based metabolomics platform for metabolic phenotype analysis. J. Biosci. Bioeng. 2011, 112, 292-298. [CrossRef]

38. Chong, J.; Wishart, D.B.; Xia, J. Using MetaboAnalyst 4.0 for comprehensive and integrative metbolomics data analysis. Curr. Protoc. Bioinform. 2019, 68, e86. [CrossRef]

(C) 2020 by the authors. Licensee MDPI, Basel, Switzerland. This article is an open access article distributed under the terms and conditions of the Creative Commons Attribution (CC BY) license (http://creativecommons.org/licenses/by/4.0/). 